\title{
AOR
}

Selected Papers of \#AolR2020:

The $21^{\text {st }}$ Annual Conference of the

Association of Internet Researchers

Virtual Event / 28-31 October 2020

\section{\#BABIESOFINSTAGRAM: THE DIGITALLY MEDIATED LIVES OF 'ASPIRING' BABY MODELS AND BRAND REPS}

\author{
Alexandra Ruiz-Gomez \\ ESIC Business \& Marketing School (Spain) \\ Diana Gavilan \\ Universidad Complutense de Madrid \\ Maria Avello \\ Universidad Complutense de Madrid
}

\section{Introduction}

Sharenting, a term that refers to parents sharing the lives and images of their children in digital spaces (Leckart, 2012), has become an extended phenomenon (Blum-Ross \& Livingstone, 2017). Emerging literature and popular media reveal that a growing number of parents practice sharenting to obtain financial advantages (Archer, 2019). Children not only appear as part of their parents' accounts, but well-known influencers and celebrities also create accounts on behalf of their children that get verified by platforms. This not only contributes to normalize sharenting, but it seems to encourage ordinary parents to create accounts for their children. Research on sharenting driven by financial gain is urgently needed to understand how children's images are used and how their lives are being commodified (Archer, 2019).

This paper is part of an on-going study of baby accounts created by ordinary parents to reach audiences outside friends and families. This study aims to provide insights into the growing phenomenon of commercial forms of sharenting. The investigation takes place on Instagram where people perceive digital fame and rewards to be more easily attainable than other social media sites (Harrison, 2018). The question guiding this research is: What sort of practices and technical affordances are used in baby accounts to attract visibility and attention of brands? 


\section{Methods}

A qualitative exploratory approach is used to examine baby accounts and posts created by parents. For the purposes of this study, we define baby accounts as parent-run accounts where a child or several children 0-3 years old appear in more than $90 \%$ of the content. Only accounts without activated privacy settings are included. Profile descriptions, such as 'account run by mommy' are used to determine if accounts are managed by parents. A multi-step approach using hashtags allowed access to these specific types of accounts (see Figure 1).

An external hashtag tool helped generate 68 variations of the broad term 'baby' and identify hashtags frequently tagged together in baby posts. We opted for hashtags combining two or more words as this suggests a more deliberate use. Two popular hashtags (\#babiesofinstagram and \#igbabies) were selected based on relevance, cooccurrence frequency and volume to extract a total of 20,284 posts of babies. To obtain a 'clean' data set of posts from baby accounts, 4,730 random posts were visually checked on Instagram using post links. A smaller data set of 308 posts was created through a random process of selecting and discarding posts when the account originating the posts did not fit the criteria.

Customized primary data was collected of 158 unique baby accounts behind the posts in our sample to provide a richer context to our analysis. Annotations included the user handle, child's gender, and whether the account monetized by visually checking posts and profile information to look for brand partnerships and promotional discounts. Content analysis was conducted on the posts by observing images, captions, and hashtags.

\section{Figure 1: Multistep approach to identify baby accounts}

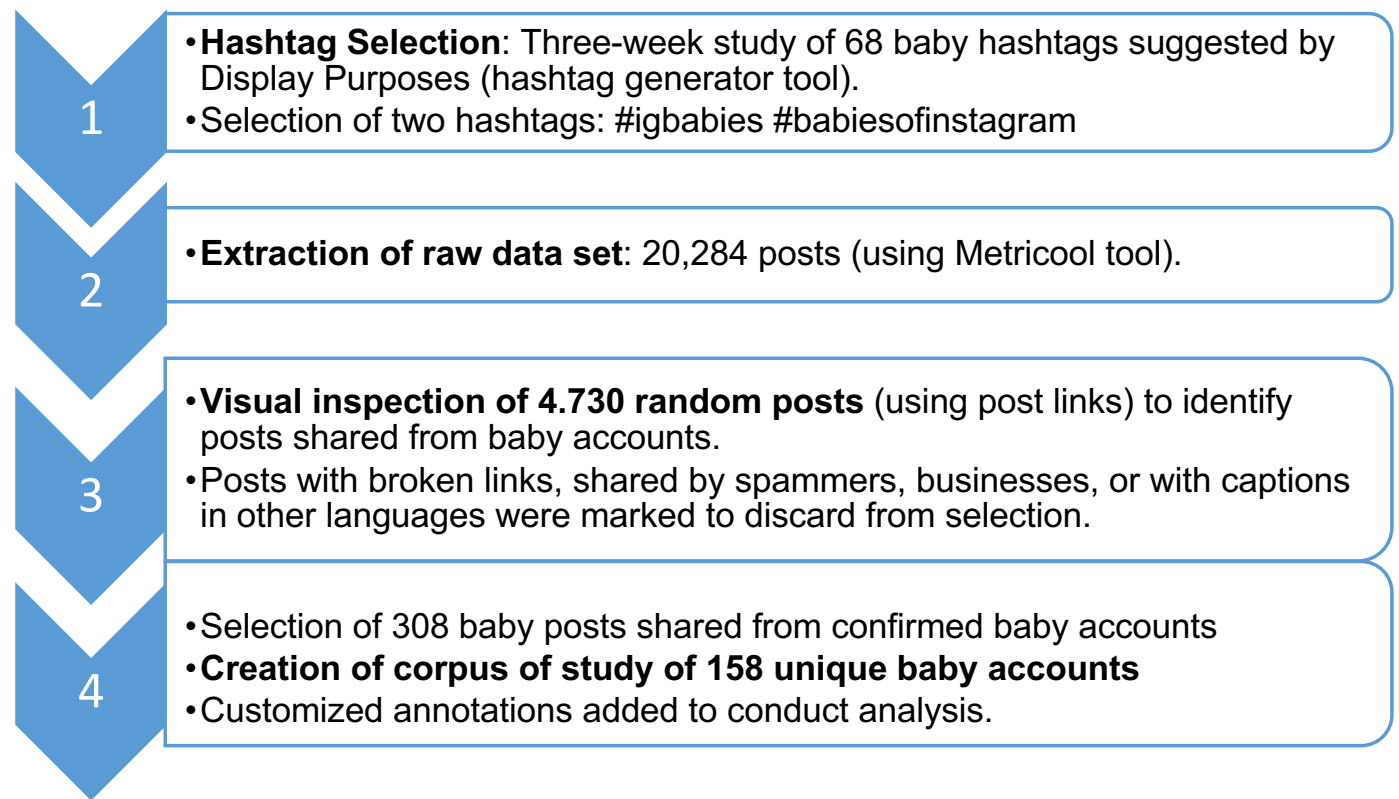

\section{Findings}


Findings reveal that baby accounts in our study are predominantly created to seek financial opportunities in the fashion industry. This is observed in the post images where brands are mentioned or tagged and children appear in carefully staged poses that emphasize the baby's looks and the clothes worn. The choice of hashtags added to the posts, such as \#babymodel or \#babybrandrep, suggest a willingness to participate in baby model contests and brand representation (commonly known as 'Brand rep') searches. The commercial motivations of these accounts are also evident in post captions and profile descriptions such as "14-month-old fashionista and aspiring baby model", "BrandAmbassador" or "DM for collabs" and post captions like "Use code BABYDANIELLE to get $15 \%$ off discount of this lovely romper".

\section{Discussion and conclusions}

There is much debate about the role of parents in the digitally mediated lives of children, but very little is known about the specific practices used by ordinary parents to disseminate the images of their children on social media to reach brands and seek monetization opportunities. By studying the accounts created on behalf of babies on Instagram, this study aims to shed light on unexplored behaviors behind evolving sharenting practices.

Past studies on sharenting practices have focused on parents' motivations for sharenting through surveys and interviews (Ammari, Kumar, Lampe, \& Schoenebeck, 2015; Blum-Ross \& Livingstone, 2017). Parents have indicated motivations such as creating digital albums for posterity, sharing content of a child's milestones with relatives and friends, or seeking advice or support from other parents (Archer, 2019). However, the accounts in this study reveal different motivations. In these accounts, the lives and images of children are packaged to obtain rewards such as brand partnerships and free or discounted products or services through brand representations.

Using children to sell products is nothing new. Children have been used in traditional advertising to appeal emotionally to women by arousing maternal love (Kinsey, 1987). What is significantly different today is the scale in which children's lives are being commodified by parents. Furthermore, another issue involves the demands placed on the children appearing in accounts that seek monetization or that already monetize through brand representations. Posts of babies photographed during naptimes with multiple changes of outfits in carefully staged flat-lays illustrate some of these demands. This is not just of theoretical interest to researchers, but it also has implications for society at large.

Numerous scholars have raised concerns about children's right to privacy and rights as participants in commercial content. However, to date, there is inadequate systematic regulation of children's rights regarding their participation in digital spaces when monetization occurs, even though some countries have created self-regulatory guides (Van Der Hof et al., 2019).

This investigation extends emerging research on the growing presence of children on digital spaces by exploring parent-run baby accounts driven by financial gain. The larger 
implications of our study suggest that as sharenting evolves into a potential commercial endeavor, children's privacy is further exposed to the eyes of strangers.

\section{References}

Ammari, T., Kumar, P., Lampe, C., \& Schoenebeck, S. (2015). Managing Children's Online Identities: How Parents Decide what to Disclose about their Children Online. Proceedings of the 33rd Annual ACM Conference on Human Factors in Computing Systems, 1895-1904. ACM.

Archer, C. (2019). How influencer 'mumpreneur' bloggers and 'everyday' mums frame presenting their children online. Media International Australia, 1329878X1982836. https://doi.org/10.1177/1329878X19828365

Blum-Ross, A., \& Livingstone, S. (2017). "Sharenting," parent blogging, and the boundaries of the digital self. Popular Communication, 15(2), 110-125. https://doi.org/10.1080/15405702.2016.1223300

Kinsey, J. (1987). The Use of Children in Advertising and the Impact of Advertising Aimed at Children. International Journal of Advertising, 6(2), 169-175. https://doi.org/10.1080/02650487.1987.11107013

Leckart, S. (2012, May 12). 'The Facebook-Free Baby' Are you a mom or dad who's guilty of 'oversharenting'? The Wall Street Journal.

Van Der Hof, S., Verdoodt, V. V., Leiser, M., Simone, van der H., Verdoodt, V. V., \& Leiser, D. M. (2019). Child Labour and Online Protection in a World of Influencers. The Regulation of Social Media Influencers. Date: 2019/01/11. https://doi.org/10.2139/ssrn.3458379 